\title{
EFFECT OF RYE ERGOT ON THE PREGNANT SHEEP
}

\author{
J. G. GREATOREX AND P. G. MANTLE \\ Department of Medicine, Royal Veterinary College Field Station, North Mimms, Herts, \\ and Biochemistry Department, Imperial College, London, S.W.7
}

(Received 29th March 1973)

\begin{abstract}
Summary. Milled ergot (Claviceps purpurea) sclerotia containing ergotamine $(0.25 \%)$, alkaloid-free ergot and alkaloid-free ergot to which ergotamine tartrate had been added were administered to pregnant sheep, either orally or through a ruminal cannula. The daily dosage (administered as three sub-doses) of ergot sclerotia was $0.4 \mathrm{~g} / \mathrm{kg}$ body weight and, where alkaloid was involved, ergotamine was presented at $1 \mathrm{mg} / \mathrm{kg}$. The milled ergot, irrespective of route of administration, produced severe illness. In some ewes, there was also uterine involvement. By contrast, alkaloid-free ergot had no effect even when the daily dosage was increased by $50 \%$. When ergotamine tartrate was added to the alkaloidfree ergot tissue, however, the mixture elicited a marked clinical response with abortions. Dosage of animals under field conditions during the 11 th week of pregnancy gave either an immediate or a delayed response which resulted in acute illness in the ewe but did not affect pregnancy. Dosage of animals under loose box conditions at later stages in pregnancy resulted in less acute illness in the ewe but caused fetal death in three out of four animals at or beyond the $3 \frac{1}{2}$-month stage of pregnancy.
\end{abstract}

\section{INTRODUCTION}

Ergot has long been thought to be one of several causes of reproductive failure in herbivorous mammals, particularly cattle, sheep and pigs. As far as the present authors are aware, no scientifically based experimental assessment of the rôle of ergot in reproductive failure in sheep or cattle has been reported in the literature. Thus the present study, being an extension of previous experiments on non-pregnant sheep (Greatorex \& Mantle, 1973), was designed to provide a basis for assessing the danger of ergot during pregnancy in this species.

\section{MATERIALS AND METHODS}

\section{Ergot sclerotia and ergot alkaloid}

The Czechoslovakian rye ergot sclerotia, containing $0.29 \%$ total alkaloids of which the principal component was ergotamine, and the ergotamine tartrate B.P. used in the present studies were from the same batches as were used previously by Greatorex \& Mantle (1973).

Animals. Nine pregnant crossbred Cheviot ewes were examined initially for clinical defects. At intervals during experiment, samples of blood taken from the jugular vein into bottles containing sequestrine were examined for general 
haematological parameters and calcium values. Faecal examinations were carried out to estimate the parasitic burden.

Seven sheep were housed during mild spring weather in loose boxes $(12 \mathrm{ft} \times$ $10 \mathrm{ft}$ ) and bedded on wheat straw. They were fed good meadow hay with a plentiful supply of water. The loose boxes were cleansed daily.

Two animals were tested during cold winter weather on pasture consisting mainly of perennial rye grass and wild white clover. The sheep were enclosed in wattle pens (approximately $8 \mathrm{yd}^{2}$ in area) and moved daily to fresh pastures. Good meadow hay was also provided.

Dosing. Oral dosing of aqueous suspensions of powdered (60 mesh) ergot was achieved using a narrow-necked drenching bottle. Similar suspensions were introduced, through a plastic tube attached to a funnel, directly into the rumen of animals which had been cannulated by the method of Phillipson \& Innes (1939).

The daily dose of ergot was divided into four equal parts and administered at $09.00,12.30$ and 16.30 hours (double dose). This was to simulate the more continuous ingestion of ergot which could occur during normal grazing. The duration of experimental dosing was generally determined by the response of each animal, as it was not the intention to cause mortality in the ewe.

\section{Preparation of alkaloid-free ergots}

Milled ergot sclerotia $(1.33 \mathrm{~kg})$ were mixed with sodium bicarbonate $(150 \mathrm{~g})$ and distilled water $(200 \mathrm{ml})$, packed into a glass column $(15 \times 60 \mathrm{~cm})$ and then percolated slowly in the dark for 2 days with analar diethyl ether (11 litres) followed by acetone ( 5 litres). The ether extract was extracted with $3 \%$ tartaric acid $(5 \times 600 \mathrm{ml})$ to remove the alkaloid and the alkaloid-free ether was evaporated to leave the ergot oil.

The acetone was evaporated from the acetone extract, and $3 \%$ tartaric acid $(100 \mathrm{ml})$ and ether $(200 \mathrm{ml})$ were added to the residue. After shaking, the remaining oil and alkaloid were partitioned into the organic and aqueous phases, respectively. The ether phase was evaporated and added to the oil obtained from the ether percolate.

The combined ergot oil extract was mixed with the extracted ergot tissue, from which residual acetone had been removed in a stream of warm air $\left(27^{\circ} \mathrm{C}\right)$, and the reconstituted alkaloid-free ergot was later formulated for dosing by suspending in water.

The combined tartaric acid extracts were adjusted to $\mathrm{pH} 8.5$ with $\mathrm{NH}_{4} \mathrm{OH}$, extracted twice with chloroform and the combined chloroform extract was taken to dryness. The total weight of alkaloid thus extracted from the ergot agreed closely with the amount expected from previous assays (Greatorex \& Mantle, 1973) of the batch of ergot sclerotia. A small sample (3 g) of the extracted ergot was subsequently assayed (Mantle, 1967) and found to be alkaloid-free.

\section{Reconstitution of ergot}

The amount of ergotamine tartrate which was added to alkaloid-free ergot in order to reconstitute as nearly as possible the complete ergot (though with the 
alkaloid 'loosened' from the tissues) was calculated on the basis of an original sclerotial ergotamine content of $0.25 \%$.

\section{RESULTS \\ EXPERIMENT 1}

The results of a comparison of the effect of ergot sclerotia, alkaloid-free ergot, and alkaloid-free ergot to which ergotamine tartrate was added at the rate of $1 \mathrm{mg}$ ergotamine/ $\mathrm{kg}$ body weight to restore the normal alkaloid content are summarized in Table 1 (Sheep 1 to 7).

\section{(A) Clinical responses following daily administration of milled ergot sclerotia}

(1) Administration by mouth. Sheep 1 showed a marked respiratory dyspnoea with a 'thumping' type of action 4 days after the commencement of oral dosing. By the 6th day, diarrhoea was in evidence and the extremities of the hind limbs and ears were extremely cold. Although there was some abdominal straining, there was no evidence of any discharge at the vulva. This animal was destroyed on humane grounds on account of the presence of extensive pneumonia on the 9 th day following the commencement of dosing.

At post-mortem examination, dead twin lambs, considered to be full term, were found in the uterus. The fetal membranes and cotyledons showed evidence of necrosis. One lamb had broken free of its membranes with its head located in the cervix. The thoracic cavity contained a small volume of clear fluid. The right apical and cardiac lobes showed areas of congestion and consolidation. The left antro-ventral lobes were similarly affected but to a lesser degree. Haemorrhages were present in the epicardium. Mediastinal and bronchial lymph nodes were enlarged and congested.

Widespread haemorrhage was present in the abomasum, duodenum and proximal ileum but was less in evidence in the distal parts of the intestines.

There was no evidence of haemorrhage formation in the subcutaneous and periosteal tissues in the region of the fetlocks, nor was there any necrosis of the tip of the tongue. The ears and tail were free from lesions.

(2) Administration by a ruminal cannula. Sheep 2, approximately 3 months pregnant, showed no clinical symptoms during the 3-day dosing period but in the immediate withdrawal period the ewe became dull and refused food. Breathing became dyspnoeic with a 'thumping' type of action. The extremities of the hind legs became cold but the temperature of the fore feet remained normal. By the 6th day, salivation had commenced and necrosis of the tongue was evident. On the following day (7th), the muzzle and face had become oedematous and the tip of the tongue showed indications of sloughing.

By the 26th day after dosing, the ewe aborted a dead fetus of approximately 4 months. Within $24 \mathrm{hr}$, there was evidence of retention of fetal membranes and an endometritis. The animal became extremely dull, unable to eat or drink because of tongue lesions and was destroyed. The post-mortem examination revealed the carcase to be debilitated and to contain very little subcutaneous fat. The mucosae of the abomasum, small and large intestines showed extensive inflammation and haemorrhage formation. Haemorrhages were also present in 


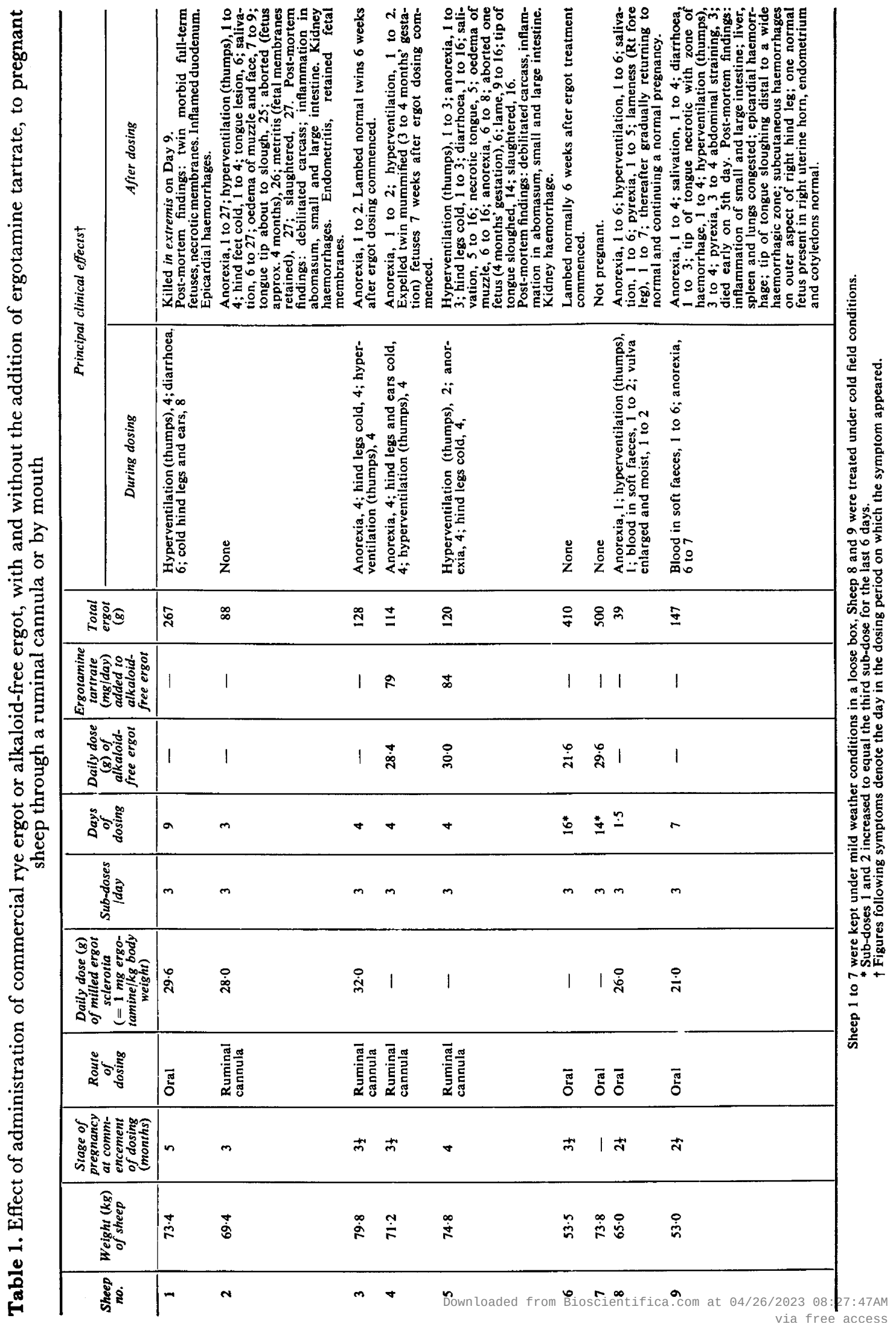


the kidney cortex. The tip of the tongue showed an area of necrosis distal to a zone of haemorrhage separating the diseased and normal tongue tissue. An endometritis was evident and the cotyledons of the retained fetal membranes were necrotic.

Sheep 3 developed anorexia, increased respiration and coldness of the extremities of the hind legs after 4 days of dosing. The symptoms continued for a further 2 days after dosing was stopped. The sheep gradually returned to normal and lambed normal twins 6 weeks after dosing commenced.

(B) Clinical responses following daily administration, by a ruminal cannula, of alkaloidfree ergot to which ergotamine tartrate had been added

Sheep 4 became dull and off food 4 days after the commencement of dosing. Respirations showed characteristic 'thumping'. The extremities of both hind legs and the ears were noticeably cold on palpation. Anorexia and hyperventilation continued for 2 days after dosing was stopped and the ewe made a gradual and uneventful recovery. Mummified twin fetuses of 3 to 4 months' gestation were expelled 7 weeks after dosing commenced.

Sheep 5 developed an increased respiratory rate 2 days after dosing commenced and became dull although appetite was maintained. On the 4th and last day of dosing, there was loss of appetite and coldness of the extremities of the hind limb. The animal's temperature remained normal and there was no evidence of diarrhoea or tongue lesions. These symptoms continued after dosing was stopped and diarrhoea became evident. The liquid faeces were light brown in colour and offensive in odour. As recorded previously (Greatorex \& Mantle, 1973), the onset of salivation coincided with the animal standing over the water trough, drooling saliva from the commisures of the mouth. This sign also signified the onset of necrosis of the tip of the tongue which became yellowish in colour with a zone of haemorrhage separating the diseased and normal tissue. Oedema of the muzzle and a rise in temperature was also apparent. Straining commenced on the 6th day and a lamb of 4 months' gestation was expelled within $6 \mathrm{hr}$. The fetal membranes were expelled and there was no subsequent evidence of a vaginal discharge. On the 9th day, the ewe became lame in the left hind leg, lameness persisting until the animal was slaughtered on the 16th day, by which time the tip of the tongue had sloughed leaving a small ulcerated, though healing, area.

At post-mortem examination, the carcass was seen to be debilitated and the abdominal cavity contained a small amount of blood-stained serous fluid. The rumen, reticulum and omasum were free from lesions. Careful washing of the abomasal wall revealed the mucosae to be inflamed and dark purple in colour, with greenish-black pigmented areas on the spiral folds. Multiple petechial haemorrhages were also visible. Both the small and large intestines showed areas of lesion similar to those in the abomasum. The kidneys were congested with many subcapsular haemorrhages. The liver was also congested. Apart from the tongue lesion, no other abnormalities were found in the mouth, pharynx, larynx, trachea, heart or lungs. Examination of the extremities and ears did not reveal any oedema or haemorrhages in the subcutaneous or periosteal tissues. 
(C) Clinical response following daily oral administration of alkaloid-free ergot

Sheep 6 showed no clinical abnormalities and the ewe gave birth to a normal lamb 6 weeks after ergot treatment commenced.

Sheep 7 also showed no clinical abnormalities, but this ewe was eventually found to be non-pregnant.

Haematology. No significant haematological changes were observed in any of the experimental animals with the exception of Sheep 2 which showed a neutrophilia and 'shift' to the 'left' in consequence of the endometritis which followed abortion.

\section{EXPERIMENT 2}

The results of a comparison of the effects of daily administration of milled ergot sclerotia, providing $1 \mathrm{mg}$ ergotamine $/ \mathrm{kg}$ body weight, on sheep at different stages of pregnancy are summarized in Table 1 (Sheep 1 to 3 and 8 and 9).

\section{(A) During the 11 th week of pregnancy, in the field in cold weather}

There was no evidence that the ergot dosing had any effect on pregnancy although, accentuated by the field conditions in the cold, the ewes showed an acute clinical response which resulted in the death of one animal. There was a marked difference in the onset of symptoms in these animals. Whereas Sheep 8 showed an acute response within 1 day of commencing dosing, a delay of about 7 days occurred in Sheep 9. The symptoms were similar to those described in Exp. 1.

The post-mortem findings in Sheep 9, summarized in Table 1, corresponded to those described for Sheep 1, 2 and 5 and were generally similar to those previously reported (Greatorex \& Mantle, 1973). It was notable, however, that, in spite of the acute changes in other body tissues, the uterus and its contents were normal.

(B) During the 3- to 5-month stage of pregnancy, in a loose box in mild weather

The responses of Sheep 1 to 3 have already been described in detail in Exp. 1 . Dosing for 3 days at 3 months of pregnancy had no immediate effect but abortion occurred 1 month later. Dosing for 4 days at $3 \frac{1}{2}$ months of pregnancy did not affect gestation but dosing for 9 days near term resulted in fetal death.

\section{DISCUSSION}

Whereas alkaloid-free ergot had no effect on the experimental sheep, the ergot in which alkaloid was present within the fungal tissues, and also that in which extracted alkaloid had been reconstituted by admixture with a solution of ergotamine tartrate, elicited a marked response.

Although administration of milled ergot directly into the rumen through a cannula had no immediate effect, there followed a progressive deterioration of the ewes which involved not only failure of the pregnancy but also vascular disturbance, especially in the tongue, and extensive intestinal inflammation. In the absence of any evidence of other factors which may be associated with pregnancy failure in the sheep, it may be reasonable to conclude that both abortion (Sheep 2) and retention of morbid fetuses (Sheep 1) were the result of 
the administration of ergot. It is possible, however, that the abortion sustained by Sheep 2 a month after ergot dosing commenced could not have been directly due to the ergot. Variability in the response of the individual animals to ergot was demonstrated by Sheep 3 which, though showing transitory clinical effects, maintained an uninterrupted pregnancy and produced normal lambs. This variability is in accord with previous field observations by G. H. Arthur and J. C. Greatorex (personal communication). Further variability in the rate of development of acute illness was evident in the two ewes (8 and 9) which were dosed together under field conditions.

When ergotamine was mixed with alkaloid-free ergot, and may therefore have been more readily available for absorption within the gastro-intestinal tract, the two sheep (4 and 5) which were dosed for only 4 days at about 4 months' gestation both suffered fetal death within 10 days of commencing dosing.

Although the present experiments have insufficient replication to allow detailed comparison between the groups of animals receiving the two forms of alkaloid-containing ergot, there was indication that there had been a more acute response of ewes and fetuses to the ergot tissue in which the alkaloid had been reconstituted and was thus not tightly bound to the constituent fungal cells.

The more acute response of pregnant sheep compared to that (Greatorex \& Mantle, 1973) of non-pregnant animals which were dosed with ergot at the equivalent rate of $1 \mathrm{mg}$ ergotamine tartrate $/ \mathrm{kg} /$ day, is probably consequent on the inactivity of the tartrate radical $(10 \mathrm{mg}$ ergotamine $=8.8 \mathrm{mg}$ ergotamine base). It is also possible that the extra weight of uterine contents should be subtracted from the total weight of the pregnant sheep in order to find the weight to which the absorbed dose of ergot alkaloid applies. This disparity was less important in Sheep 8 and 9 where, in the 11 th week of pregnancy, the uterine contents would have weighed less. Ergot did not, however, affect this stage of pregnancy although it elicited a general response which appeared to be more acute than that observed in any other treatment group. This supports the suggestion that ergot is most toxic to ruminants under field conditions (Greatorex \& Mantle, 1973).

It was notable that two (Sheep 2 and 5) of the four animals to which ergotcontaining ergotamine was administered through a ruminal cannula developed tongue lesions. This indicates that the tongue lesions were not due to the topical effect of ergot and, with the addition of the findings in Sheep 9, confirms previous reports (Cunningham, Swan \& Hopkirk, 1944; Greatorex \& Mantle, 1973) that the tongue of the sheep is commonly affected in ergot poisoning.

There are three ways in which the known pharmacological properties of ergotamine might cause pregnancy failure. First, ergotamine is an oxytocic drug (Hofmann, 1972) which, by stimulating contraction of the myometrium, may cause either increased uterine tone or more violent contractions. Fetal death, especially during the later part of pregnancy, may result from impaired gaseous exchange between maternal and fetal circulations or by disruption of placentation. Secondly, endothelial damage to end arteries/arterioles, observed in recent experimental studies on gangrenous ergotism in the sheep (Greatorex \& Mantle, 1973) may extend also to uterine cotyledon tissue resulting in vascular blockage, ischaemia and necrosis of cotyledons. Thirdly, ergotamine 
may cause hypothalamic stimulation leading to endocrine imbalance. In the mouse, ergotamine causes implantation failure (Mantle, 1969) and it is probable that this is mediated through the same mechanism of prolactin inhibition as has been demonstrated for closely related ergot alkaloids (Edwardson \& Macgregor, 1969; Finn \& Mantle, 1969). Ergotamine also causes agalactia in the pig, presumably through prolactin inhibition (Nordskog \& Clarke, 1945), and the failure of the same batch of ergot sclerotia as used in the present studies to affect the implantation stage of pregnancy in the pig (Bailey, Wrathall \& Mantle, 1973) is in accord with the absence of prolactin-induced decidualization in this species (Amoroso, 1952).

The concentration of prolactin in the maternal plasma of the sheep has been measured throughout pregnancy (McNeilly, 1971) and a sharp increase from the low levels during early pregnancy occurred towards the end of the 4th month. It is not yet clear, however, whether pituitary prolactin is involved in the maintenance of pregnancy in the sheep, especially as progesterone is not of luteal origin but is synthesized within the placenta. Thus, the apparent coincidence between the stage of high maternal plasma prolactin titres and sensitivity to ergotamine by fetuses of more than $3 \frac{1}{2}$ months' gestation may not necessarily imply that ergotamine suppressed prolactin titres or even that this disturbed the pregnancy. A more likely explanation is that the fetal death was caused by the oxytocic effect of ergotamine, possibly augmented by ischaemic necrosis of the cotyledons.

The ergot sclerotia used in the present studies were specially selected for their content of only one principal pharmacologically active componentergotamine. Other ergot alkaloids, notably the ergotoxine group (ergocornine, ergocristine and ergokryptine), ergometrine and ergosine, commonly occur as components of the total alkaloid content of $C$. purpurea sclerotia. Sometimes, one of these alkaloids may be the principal one, and their varying potencies in the pharmacological spectrum of activity (Hofmann, 1972) thereby confer on the ergots different degrees of potency with regard to oxytocic, vasopressor or centrally mediated effects on reproduction.

A suspected epidemic of ergot poisoning in sheep was observed in 1948 (A. D. Osborne, personal communication). Forty-one out of 120 pregnant ( 3 to 4 months) ewes aborted 7 to 10 days after commencing to feed on a supplement containing ergotized ryegrass seed. Ergots had been found to comprise $4 \%$ of the supplement. A large proportion of the flock developed diarrhoea and about half of the ewes which aborted died. Post-mortem examination showed extensive inflamed gastro-intestinal lesions. The present studies show that it is possible that a daily intake of less than $1 \mathrm{mg}$ of the ergotized supplement could have caused the effects observed by Osborne. An additional contrasting observation by Osborne that cattle refused to eat the ergotized supplement implies that if grazing sheep, which are normally much more selective against the flowering heads than cattle, are forced to turn to ergotized inflorescences, they may easily accept a considerable amount of ergot.

Under natural conditions in this country, sheep would not normally have access to pasture ergot during late pregnancy but ergotized hay or seed as a winter feedstuff supplement should be avoided. 


\section{ACKNOWLEDGMENTS}

We gratefully acknowledge the gift of ergotamine tartrate B.P. and rye ergot sclerotia from the Wellcome Foundation Ltd. We also thank Professor F. R. Bell for inserting the ruminal cannulae, Miss J. Smith for technical assistance and Mr S. Snaith for attending the sheep.

\section{REFERENCES}

Amoroso, E. C. (1952) Placentation. In Marshall's Physiology of Reproduction, Vol. II. Ed. A. S. Parkes. Longmans Green, London.

Bailey, J., Wrathall, A. E. \& Mantle, P. G. (1973) The effect of feeding ergot to gilts during early pregnancy. Br. vet. J. 129, 127.

Cunningham, I. J., Swan, J. B. \& Hopkirk, C. S. M. (1944) The symptoms of ergot poisoning in sheep. N.Z. Jl Sci. Technol. A, 26, 121.

EdWARdson, J. A. \& MAcGregor, L. A. (1969) The effect of progesterone and some other agents on the failure of pregnancy produced by feeding agroclavine, an ergot alkaloid, in the rat. $B r . \mathcal{J}$. Pharmac. Chemother. 35, 367P.

FinN, C. A. \& MantLe, P. G. (1969) The influence of agroclavine on the preparation of the uterus for implantation in the mouse. F. Reprod. Fert. $20,527$.

Greatorex, J. G. \& Mantle, P. G. (1973) Experimental ergotism in sheep. Res. vet. Sci. 15, 337.

Hofmans, A. (1972) Ergot-a rich source of pharmacologically active substances. In Plants in the Development of Modern Medicine. Ed. T. Swain. Harvard University Press.

MaNeilly, J. R. (1971) A solid phase radioimmunoassay for ovine prolactin. 7. Endocr. 49, 141.

MANTLE, P. G. (1967) Emergence and phytopathological properties of a new strain of Claviceps purpurea (Fr.) Tul. on rye. Ann. appl. Biol. 60, 353.

MANTLE, P. G. (1969) Interruption of early pregnancy in mice by oral administration of agroclavine and sclerotia of Claviceps fusiformis. 7. Reprod. Fert. 18, 81.

Nordskog, A. W. \& ClaARKe, R. T. (1945) Ergotism in pregnant sows, female rats and guinea pigs. Am. 7. vet. Res. 6, 107.

Phillipson, A. T. \& Innes, J. R. M. (1939) Permanent stomach fistulae in ruminants. $Q . \mathcal{J} l$ exp. Physiol. 24, 333. 